\title{
Ipilimumab-nivolumab therapy causing STEMI in a melanoma patient: A case report
}

\author{
Ahmed Zaid Alkhathlan*1, David S. Tofovic ${ }^{1}$, Claire Sullivan², Anjan Gupta², Sanjay Rajagopalan² \\ ${ }^{1}$ Department of Internal Medicine, University Hospitals Cleveland Medical Center, Cleveland, United States \\ ${ }^{2}$ Divison of Cardiovascular medicine, Harrington Heart and Vascular institute, Cleveland, United States
}

Received: June 26, 2017

Accepted: July 11, 2017

Online Published: July 19, 2017

DOI: $10.5430 /$ crim.v4n3p57

URL: https://doi.org/10.5430/crim.v4n3p57

\begin{abstract}
The combination of ipilimumab and nivolumab has shown great promise in improving survival in patients with advanced melanoma. However, these novel agents are not without side effects, with adverse events occurring in up to $55 \%$ of patients on combination therapy. We report a case of ST-elevation myocardial infarction (STEMI) with resultant new severe systolic heart failure and left ventricular thrombus in a middle-aged woman with metastatic melanoma on ipilimumab-nivolumab therapy suspicious for de novo intra-arterial thrombus formation. We hypothesize that this is likely due to an immune-related adverse event, a documented phenomenon in patients on this combination therapy. To the best of our knowledge, this is the first case in patients on ipilimumab-nivolumab therapy to develop STEMI due to intra-arterial thrombus formation.
\end{abstract}

Key Words: Myocardial infarction, Intra-arterial thrombus, Nivolumab, Ipilimumab

\section{INTRODUCTION}

According to the World Health Organization (WHO), 130,000 new cases of skin cancer occur every year. ${ }^{[1]}$ Within this group, metastatic melanoma, with a median survival of less than one year, is particularly lethal. ${ }^{[2,3]}$ Most recent advances in treatment include immune checkpoint-blocking antibodies, which allow cytotoxic T-cell mediated destruction of cancer cells. ${ }^{[4-6]}$ Ipilimumab, a human IgG1 monoclonal antibody that blocks cytotoxic T-lymphocyte-associated antigen 4 (CTLA-4), has been shown to be an effective agent against advanced melanoma. ${ }^{[7,8]}$ Another antibody targeted at the programmed death 1 (PD-1) receptor, Nivolumab, has been used with similar outcomes. ${ }^{[4,9]}$ The combination of both of these agents has shown great promise in improving survival in advanced melanoma. ${ }^{[10,11]}$
These novel agents are not without side effects, however. Adverse events have been reported in $22 \%-24 \%$ of patients on ipilimumab monotherapy, ${ }^{[12,13]}$ in 5\%-10\% of nivolumab patients, ${ }^{[14]}$ and in $55 \%$ of patients on combination therapy. ${ }^{[9,13]}$ These side effects include dermatitis (most common), gastrointestinal issues (including severe colitis, esophagitis, hepatitis, and pancreatitis), endocrine abnormalities (including hyperthyroidism, hypothyroidism, hypophysitis, diabetes and adrenal insufficiency), and nephritis. ${ }^{[15]}$ Furthermore, cardiac conduction abnormalities and myocarditis (including fulminant myocarditis leading to death) have been reported. ${ }^{[16-20]}$

We report a case of ST-elevation myocardial infarction (STEMI) in the setting of new intra-arterial thrombus formation, severe systolic heart failure, and left ventricular throm-

\footnotetext{
* Correspondence: Ahmed Zaid Alkhathlan, MD; Email: ahmed.alkhathlan@ uhhospitals.org; Address: Department of Internal Medicine, University Hospitals Cleveland Medical Center, Cleveland, 26500 Amhearst Cir Apt 112, Beachwood, OH 44122, United States.
} 
bus in a middle-aged woman with metastatic melanoma on ipilimumab-nivolumab therapy.

\section{CASe presentation}

The patient, a 51-year-old Caucasian female with no known coronary risk factors, was initially found to have a malignant melanoma on her back, Breslow's depth $0.5 \mathrm{~mm}$ (stage V) ${ }^{[21]}$ in 2011. Clear margins were obtained on excision via Mohs procedure. ${ }^{[22]}$ Cancer recurrence in her breast tail and axilla was diagnosed in 2016 after a core needle biopsy showed metastatic malignant melanoma with a BRAF V600E gene mutation. Positron emission tomography-computed tomography (PET-CT) detected a large hypermetabolic focus within the left axilla, right hilar lymph nodes, subcarinal lymph node, multiple pulmonary nodules within the right lower lobe, right anterior superior iliac spine, and right iliac wing. Deemed consistent with stage IV malignant melanoma TX NX M0 based on The American Joint Committee on Cancer (AJCC) $7^{\text {th }}$ edition guidelines, ${ }^{[23]}$ the patient was started on Ipilimumab/Nivolumab combination therapy. Her course was complicated by pneumonitis one week after her first cycle and grade 3 colitis, which required hospitalization for IV fluids and prednisone at $1 \mathrm{mg} / \mathrm{kg}^{[24]}$ after her third cycle. The morning after discharge, the patient developed left-sided chest tightness. On repeat admission, the electrocardiogram showed ST elevation in leads II and V3-V6 (see Figure 1).

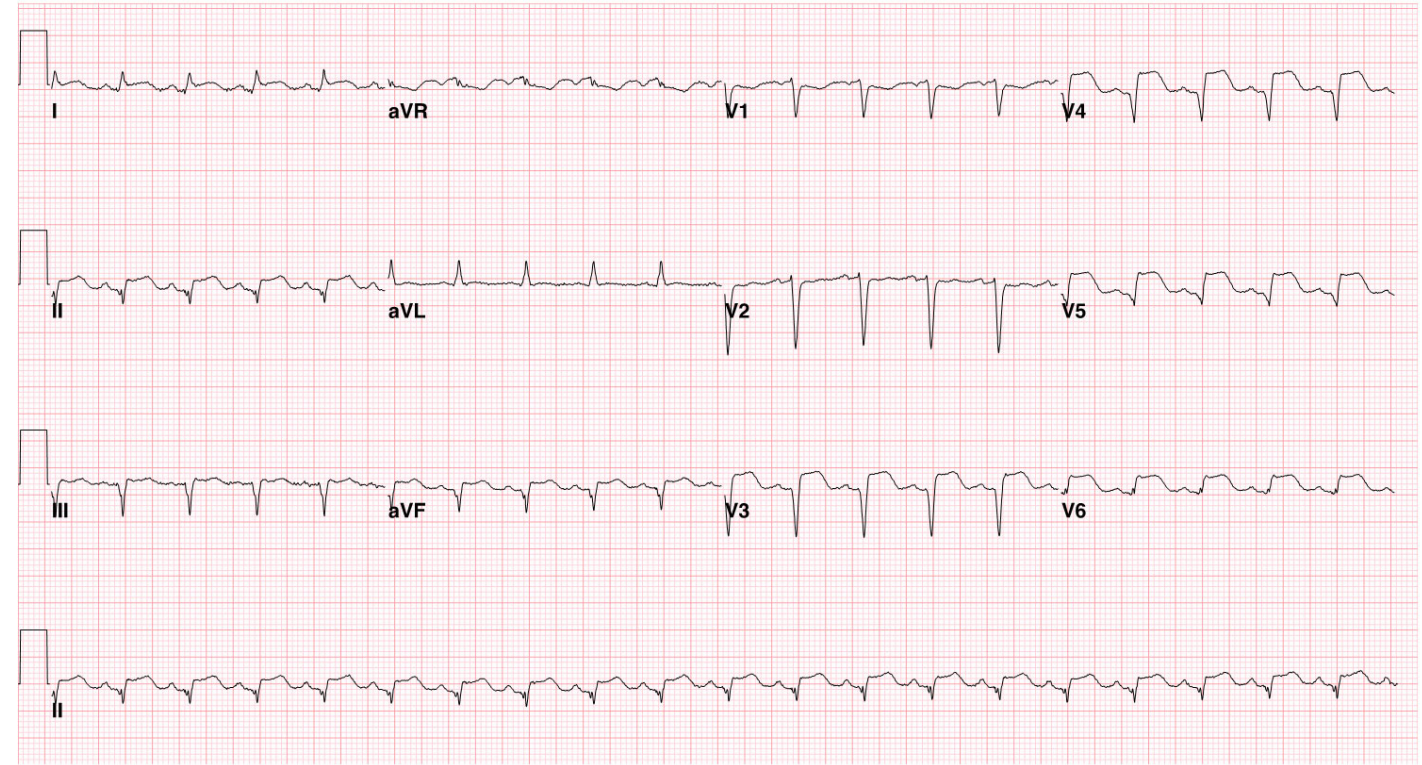

Figure 1. Admission electrocardiogram with ST elevations in leads II and V3-V6

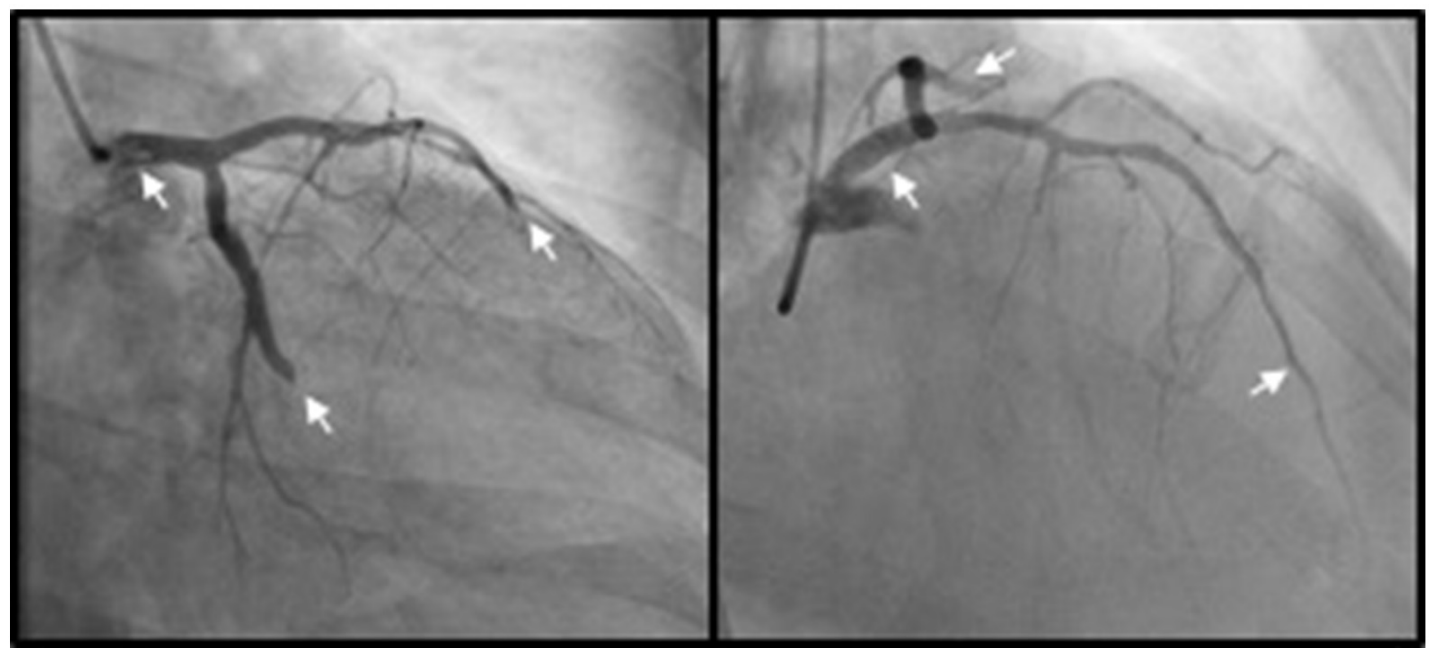

Figure 2. Pre and post-coronary invention angiography revealing left main coronary artery, left anterior descending coronary artery, and left circumflex coronary artery thrombus formation with good post-intervention results 
With a troponin-I of $8.4 \mathrm{ng} / \mathrm{ml}$, the patient was loaded with aspirin (324 mg) and ticagrelor (180 mg) and emergently underwent coronary angiography (see Figure 2). A heart catheterization revealed thrombi in the left main (LM) 75\% occlusion and Thrombolysis in Myocardial Infarction (TIMI $^{[25]}$ ) flow of 2-left anterior descending (LAD)-100\% occlusion and TIMI flow of 0 -and left circumflex (LCX)- $100 \%$ occlusion and TIMI flow of 0 . The right coronary artery did not contain thrombus. Percutaneous coronary intervention
(PCI) was performed within the LM, with a successful placement of Resolute Integrity drug-eluting stent. Aspiration thrombectomy to the LAD and LCX resulted in good return flow within these vessels. Given the low cardiac index of 1.8 and elevated LVEDP, the patient underwent Impella 2.5 and Swan-Ganz catheter placement. Post-procedurally, she was started on Eptifibatide and continued on dual antiplatelet therapy.

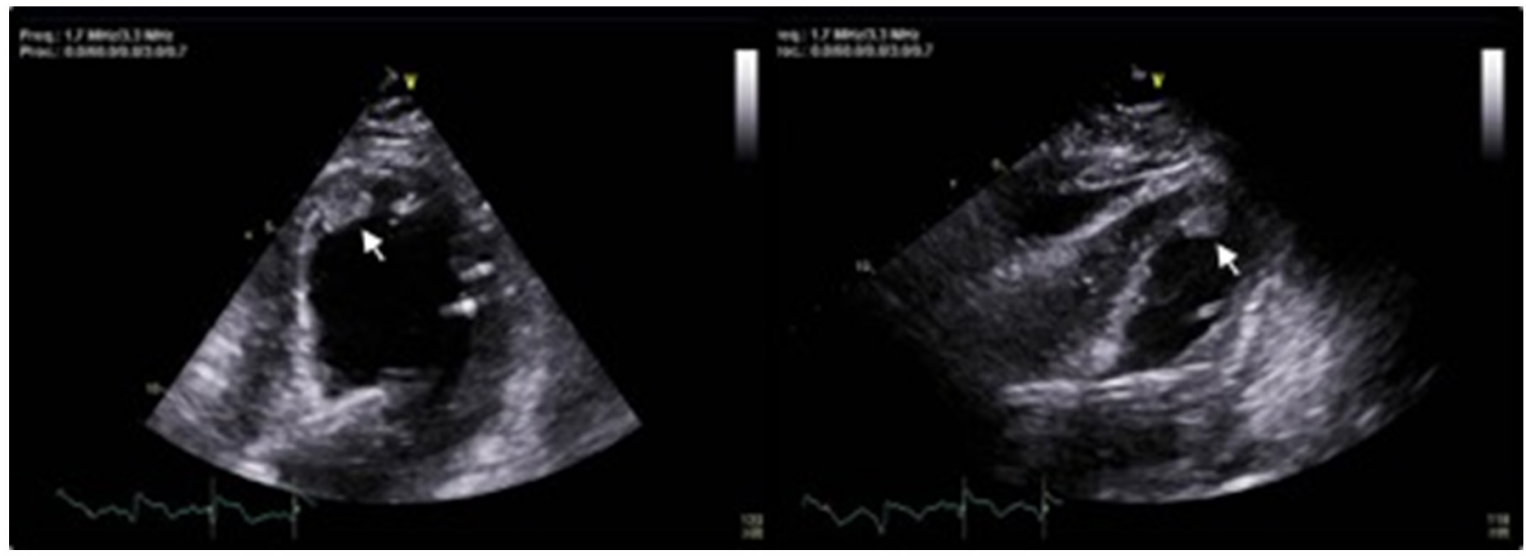

Figure 3. Transthoracic echocardiography demonstrated newly reduced LVEF and LV apical mass

Transthoracic echocardiography (TTE) revealed a left ventricular (LV) estimated ejection fraction (EF) of 20\%-25\% and LV apical mass that was concerning for thrombus vs. metastasis (see Figure 3). Given these findings, she was restarted on intravenous heparin infusion. Troponin peaked at $162 \mathrm{ng} / \mathrm{ml}$. Cardiac Magnetic Resonance (CMR) was pursued to better delineate the LV mass. A $14 \mathrm{~mm} \times 5 \mathrm{~mm}$ $\times 4 \mathrm{~mm}$ mass lesion within the LV apex adherent to the interventricular septum was noted (see Figure 4). The mass showed no enhancement with first or late pass perfusion of gadolinium, which is consistent with an LV thrombus. Extensive transmural late gadolinium enhancement consistent with nonviable myocardium involving the mid anterior, septal, and lateral myocardium as well as the entire apex was seen.

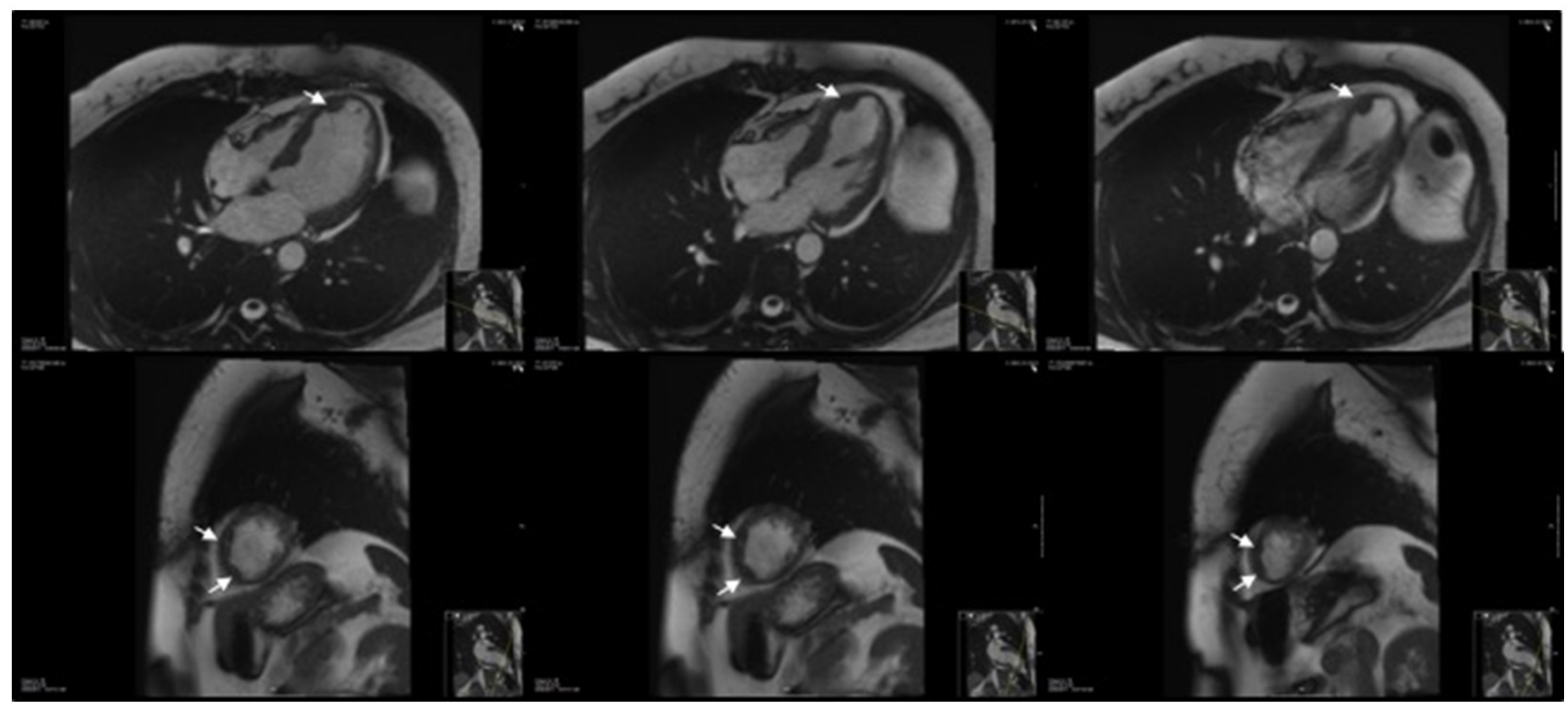

Figure 4. Cardiac magnetic resonance imaging verifies the presence of a new apical LV thrombus 
The patient was transitioned to therapeutic enoxaparin for the LV thrombus. Given continued diarrhea, she was started on high dose intravenous methylprednisolone therapy after C. difficile and stool culture tests were negative. Infliximab infusion was reinitiated. She was weaned-off of mechanical support after a gradual improvement in her symptoms. She was safely discharged home on dual-antiplatelet therapy (DAPT) and prednisone with close follow-up.

\section{Discussion}

As aforementioned, CTLA-4 and PD-1 inhibitors provide a new therapeutic option for an otherwise lethal disease. Given their recent approval, relatively little is known about their cardiovascular implications. Our patient was noted to have an STEMI, prompting emergent heart catheterization which showed diffuse left-sided coronary blockages. Given her lack of prior symptomatology, low-risk profile, otherwise clean coronary anatomy, and appearance of thrombi on catheterization, we hypothesize that these thrombi were induced by Ipilimumab/Nivolumab combination therapy.

Thoreau et al. have previously reported a case of intra-arterial thrombus formation in a patient on combination CTLA-4/PD1 inhibitor therapy requiring trans-phalangeal amputation. ${ }^{[26]}$ After extensive diagnostic evaluation that ruled out other possible causes, they similarly postulated that combination therapy induced thrombus formation. ${ }^{[26]}$ While an animal model has shown proinflammatory and proatherogenic effects of anti-PD-1 agents, ${ }^{[27]}$ it is unlikely in either of the cases that this led to an atheromatous plaque that either embolized or ruptured given the imaging findings and time course of the clinical presentation.

We further postulate that this may be an immune-mediated event, a known phenomenon with these agents. ${ }^{[28]}$ However, an exact mechanism at this time is unknown and requires further study. While most side effects are mild, $15 \%$ of such events lead to severe complications and can affect multiple organs within the body. ${ }^{[28]}$ Myositis, cardiomyopathy, and conduction aberrances have all been connected to CTLA4/PD-1 inhibitor therapy. ${ }^{[16-20]}$ To our knowledge, this is the first suspected case of de novo intra-arterial thrombus formation leading to STEMI in CTLA-4/PD-1 inhibitor therapy. Given the concern for the cardiovascular effects of these agents and growing side effect profile, increased and more aggressive screening may be warranted in certain higher-risk individuals prior to initiation of therapy.

\section{ACKNOWLEDGEMENTS}

We could like to Department of Internal Medicine and the Division of Cardiology at University Hospitals for their continued support.

\section{CONFlicts OF InTEREST Disclosure}

The authors have declared no conflicts of interest.

\section{REFERENCES}

[1] WHO I skin cancers. Available from: http://www. who.int/uv/f aq/skincancer/en/index1.html. Accessed 2/7/2017, 2017.

[2] Agarwala SS. Current systemic therapy for metastatic melanoma Expert Rev Anticancer Ther. 2009; 9(5): 587-95. PMid:19445576 https://doi.org/10.1586/era.09.25

[3] Tsao H, Atkins MB, Sober AJ. Management of cutaneous melanoma N Engl J Med. 2004; 351(10): 998-1012. PMid:15342808 https: //doi.org/10.1056/NEJMra041245

[4] Topalian SL, Hodi FS, Brahmer JR, et al. Safety, activity, and immune correlates of anti-PD-1 antibody in cancer. N Engl J Med. 2012 ; 366(26): 2443-54. PMid:22658127 https ://doi.org/10.1056/ NEJMoa1200690

[5] Hanahan D, Weinberg RA. Hallmarks of cancer: The next generation. Cell. 2011; 144(5): 646-74. PMid:21376230 https://doi.org/ $10.1016 / j . c e l l .2011 .02 .013$

[6] Schreiber RD, Old LJ, Smyth MJ. Cancer immunoediting: Integrating immunity's roles in cancer suppression and promotion. Science. 2011; 331(6024): 1565-70. PMid:21436444 https ://doi.org/10 $.1126 /$ science. 1203486

[7] Hodi FS, O’Day SJ, McDermott DF, et al. Improved survival with ipilimumab in patients with metastatic melanoma. N Engl J Med 2010; 363(8): 711-23. PMid:20525992 https://doi.org/10.1 056/NEJMoa1003466
[8] Robert C, Thomas L, Bondarenko I, et al. Ipilimumab plus dacarbazine for previously untreated metastatic melanoma. N Engl J Med. 2011; 364(26): 2517-26. PMid:21639810 https : //doi .org/10.1 056/NEJMoa1104621

[9] Wolchok JD, Kluger H, Callahan MK, et al. Nivolumab plus ipilimumab in advanced melanoma. N Engl J Med. 2013; 369(2): 122-33. PMid:23724867 https ://doi.org/10.1056/NEJMoa1302369

[10] Larkin J, Chiarion-Sileni V, Gonzalez R, et al. Combined nivolumab and ipilimumab or monotherapy in untreated melanoma. N Engl J Med. 2015; 373(1): 23-34. PMid:26027431 https ://doi.org/10 $.1056 /$ NEJMoa1504030

[11] Maverakis E, Cornelius LA, Bowen GM, et al. Metastatic melanoma a review of current and future treatment options. Acta Derm Venereol. 2015; 95(5): 516-24. PMid:25520039 https ://doi.org/10.234 $0 / 00015555-2035$

[12] O’Day SJ, Maio M, Chiarion-Sileni V, et al. Efficacy and safety of ipilimumab monotherapy in patients with pretreated advanced melanoma: A multicenter single-arm phase II study. Ann Oncol 2010; 21(8): 1712-7. PMid:20147741 https ://doi.org/10.109 $3 /$ annonc/mdq013

[13] Postow MA, Chesney J, Pavlick AC, et al. Nivolumab and ipilimumab versus ipilimumab in untreated melanoma. N Engl J Med. 2015; 372(21): 2006-17. PMid:25891304 https ://doi .org/10.1 056/NEJMoa1414428 
[14] Weber JS, D’Angelo SP, Minor D, et al. Nivolumab versus chemotherapy in patients with advanced melanoma who progressed after antiCTLA-4 treatment (CheckMate 037): A randomised, controlled, open-label, phase 3 trial. Lancet Oncol. 2015; 16(4): 375-84. https : //doi.org/10.1016/S1470-2045(15)70076-8

[15] Hofmann L, Forschner A, Loquai C, et al. Cutaneous, gastrointestinal, hepatic, endocrine, and renal side-effects of anti-PD-1 therapy. Eur J Cancer. 2016; 60: 190-209. PMid:27085692 https: //doi.org/10.1016/j.ejca.2016.02.025

[16] Johnson DB, Balko JM, Compton ML, et al. Fulminant myocarditis with combination immune checkpoint blockade. N Engl J Med. 2016; 375(18): 1749-55. PMid:27806233 https ://doi .org/10.1056/ NEJMoa1609214

[17] Mehta A, Gupta A, Hannallah F, et al. Myocarditis as an immunerelated adverse event with ipilimumab/nivolumab combination therapy for metastatic melanoma. Melanoma Res. 2016; 26(3): 319-20. PMid:27110676 https://doi.org/10.1097/CMR.0000000000 000251

[18] Gibson R, Delaune J, Szady A, et al. Suspected autoimmune myocarditis and cardiac conduction abnormalities with nivolumab therapy for non-small cell lung cancer. BMJ Case Rep. 2016; 2016: bcr2016216228.

[19] Behling J, Kaes J, Munzel T, et al. New-onset third-degree atrioventricular block because of autoimmune-induced myositis under treatment with anti-programmed cell death-1 (nivolumab) for metastatic melanoma. Melanoma Res. 2016; 27: 1.

[20] Tadokoro T, Keshino E, Makiyama A, et al. Acute lymphocytic myocarditis with anti-PD-1 antibody nivolumab. Circ Heart Fail. 2016; 9(10): e003514. PMid:27650418 https ://doi.org/10.1161/CI RCHEARTFAILURE. 116.003514

[21] Breslow A. Thickness, cross-sectional areas and depth of invasion in the prognosis of cutaneous melanoma. Ann Surg. 1970; 172(5):
902-8. PMid:5477666 https ://doi .org/10.1097/00000658-1 97011000-00017

[22] Connolly SM, Baker DR, Coldiron BM, et al AAD/ACMS/ASDSA/ASMS 2012 appropriate use criteria for mohs micrographic surgery: A report of the american academy of dermatology, american college of mohs surgery, american society for dermatologic surgery association, and the american society for mohs surgery. J Am Acad Dermatol. 2012; 67(4): 531-50. PMid:22959232 https://doi.org/10.1016/j.jaad.2012.06.009

[23] Edge SB, Compton CC. The american joint committee on cancer: The 7th edition of the AJCC cancer staging manual and the future of TNM. Ann Surg Oncol. 2010; 17(6): 1471-4. PMid:20180029 https : //doi.org/10.1245/s10434-010-0985-4

[24] US Department of Health and Human Services. Common terminology criteria for adverse events (CTCAE) version 4.03. June 14, 2010.

[25] TIMI study group. The thrombolysis in myocardial infarction (TIMI) trial. phase I findings. N Engl J Med. 1985; 312(14): 932-6. PMid:4038784 https ://doi.org/10.1056/NEJM198504 043121437

[26] Thoreau B, Gouailliervulcain F, Machet L, et al. Acute Lower Limb Ischaemia and Diabetes in a Patient Treated with Anti-PD1 Monoclonal Antibody for Metastatic Melanoma. Acta Dermato Venereologica. 2017; 97(3): 408-9. PMid:27377178 https ://doi.org/10 .2340/00015555-2504

[27] Bu D, Tarrio M, Maganto-Garcia E, et al. Impairment of the programmed cell death-1 pathway increases atherosclerotic lesion development and inflammation. Arterioscler Thromb Vasc Biol. 2011; 31: 1100-7. PMid:21393583 https://doi.org/10.1161/ATVB AHA. 111.224709

[28] Champiat S, Lambotte O, Barreau E, et al. Management of Immune Checkpoint Blockade Dysimmune Toxicities: a Collaborative Position Paper. Ann Oncol. 2016 Apr; 27(4): 559-74. PMid:26715621 https://doi.org/10.1093/annonc/mdv623 